DOI: $10.12731 / 2070-7568-2020-3-67-81$

УДК 338.45

\title{
ПОДХОДЫ К ОПРЕДЕЛЕНИЮ И ОЦЕНКЕ ЭКОНОМИЧЕСКОЙ ЭФФЕКТИВНОСТИ СИСТЕМЫ ЭКОНОМИЧЕСКОЙ БЕЗОПАСНОСТИ ПРЕДПРИЯТИЯ НЕФТЕГАЗОВОЙ ПРОМЫШЛЕННОСТИ
}

Жуков И.Ф.

Российская нефтегазовая отрасль в настоящее время находится в противоречивой ситуачии. С одной сторонь, она играет стратегическую роль как источник валютной выручки и налоговых поступлений для государственного бюджета. С другой стороны, ее устойчивость подрывают санкции и перенос добычи в места с неблагоприятными географическими и геологическими условиями. По этой причине необходимо уделять пристальное внимание обеспечению экономической безопасности российской нефтегазовой отрасли.

Цель статьи: разработка методики оценки экономической эффективности системы экономической безопасности предприятия нефтегазовой промышленности.

Методы: метод анализа и синтеза.

Результаты: Описана система показателей экономической эффективности. Определень сферы применения этих показателей. Предложена шкала оченки уровня экономической безопасности.

Ключевые слова: экономическая эффективность; система экономической безопасности; нефтегазовая отрасль.

APPROACHES TO DETERMINING AND ASSESSING THE ECONOMIC EFFICIENCY OF THE SYSTEM OF ECONOMIC SECURITY OF AN ENTERPRISE OIL AND GAS INDUSTRY

\section{Zhukov I.F.}

The Russian oil and gas industry is now in a contradictory position. On the one hand, it plays a strategic role as a source of foreign currency and tax incomes for the state budget. On the other hand, sanctions and 
complicated geographical and geological conditions of new reserves undermine its stability. This is why it is important to pay attention to the economic security of the Russian oil and gas industry.

Goal of the paper: working out of a method of evaluation of economic effectiveness of the system of economic security of a company of oil and gas industry.

Methods: method of analysis and synthesis.

Results: A system of indicators of economic effectiveness is proposed. Areas of use of these indicators are identified. A scale of evaluation of level of economic security is proposed.

Keywords: economic security; system of economic security; oil and gas industry.

\section{Введение}

Несмотря на значительное количество публикаций по проблемам экономической безопасности, выполненный нами анализ (проведенный путем поиска по ключевым словам в Национальной электронной библиотеке Elibrary.ru) показал, что в них отсутствует методика оценки эффективности системы экономической безопасности [2-9, $11,12,14-16]$. Количественные методики в области экономической безопасности относятся преимущественно к оценке уровня экономической безопасности $[4,6-9,15]$.

Отсутствие методики оценки эффективности системы экономической безопасности (СЭБ) может объясняться тем, что СЭБ сама по себе источником экономического эффекта для предприятия не является. Напротив, в обычной ситуации она, с точки зрения менеджмента, выступает в качестве источника издержек (поскольку проводимые мероприятия требуют затрат). Экономический эффект от ее функционирования носит косвенный характер: она позволяет минимизировать потери от наступления угроз. Однако поскольку эти угрозы носят вероятностный характер, и их масштаб заранее оценить не всегда возможно, оценка экономического эффекта СЭБ затруднительна. Тем не менее, есть насущная потребность в разработке методики оценки экономического эффекта СЭБ. Это связано 
с тем, что в экономике все решения принимаются на основе оценки экономического эффекта [1]. Отсутствие методики такой оценки подрывает обоснованность решений в сфере управления экономической безопасностью предприятия, снижает качество управленческой деятельности и ведет либо к необоснованным затратам на функционирование СЭБ, либо, напротив, к потерям из-за недостаточных (с учетом специфики деятельности предприятия) инвестициям в СЭБ.

В данной работе мы сформулируем наши рекомендации относительно разработки методики оценки экономической эффективности СЭБ в нефтегазовой отрасли. Отечественный нефтегазовый комплекс в настоящее время функционирует в сложных технологических, экономических и геополитических условиях, что предъявляет повышенные требования к обоснованности управленческих решений в области обеспечения экономической безопасности $[10,12]$.

\section{Цель}

Разработка методики оценки экономической эффективности системы экономической безопасности предприятия нефтегазовой промышленности

\section{Методы и материалы}

Общенаучный метод анализа и синтеза.

\section{Основные результаты}

Для оценки экономического эффекта мы предварительно предлагаем использовать непосредственно абсолютный показатель экономического эффекта, т. е. значение эффекта в денежном выражении. Использовать относительный показатель (т. е. экономическую эффективность) мы считаем неудобным. Дело в том, что, как было сказано выше, СЭБ приносит лишь косвенный экономический эффект, и поэтому, с управленческой точки зрения, информация об экономической эффективности СЭБ не несет в себе прозрачной и имеющей ясный управленческий и экономический смысл информации. Измерять экономический эффект следует путем оценки сни- 
жения потерь от наступления угроз экономической безопасности предприятия.

Можно выделить два первичных показателя экономического эффекта СЭБ:

1. Валовый экономический эффект Э

$$
\ni_{\text {вал }}=\Pi_{б}-\Pi_{э б},
$$

где

$\Pi_{6}$ - величина возможных потерь предприятия в случае наступления угроз до внедрения СЭБ;

$\Pi_{э б}-$ величина возможных потерь предприятия в случае наступления угроз после внедрения СЭБ;

2. Чистый экономический эффект Э

$$
Э_{\text {ч }}=Э_{\text {вал }}-3_{э \text { э }}
$$

где

$3_{\text {эб }}$ - затраты на внедрение и обеспечение функционирования СЭБ.

Для оценки экономического эффекта СЭБ мы будем далее использовать показатель чистого экономического эффекта Э, поскольку он соответствует логике управленческих решений: затраты на организацию какой-либо системы не должны быть больше ожидаемого эффекта от ее функционирования.

Очевидно, что все параметры, входящие в формулы (1) и (2) определяются на основе сценарного моделирования, т. е. они представляют собой математические ожидания соответствующих показателей с учетом вероятности реализации различных сценариев. В частности,

где

$$
\ni_{\text {вал }}=\sum_{i=1}^{n} p_{i}\left(\Pi_{б, i}-\Pi_{э б, i}\right),
$$

$n$ - число выявленных сценариев реализации угроз (различающихся по составу угрозу и/или их масштабу);

$p_{i}$ - вероятность реализации $i$-го сценария (задается экспертно);

$\Pi_{\sigma, i}$ - величина потерь предприятия от наступления угроз в случае реализации $i$-го сценария при отказе от внедрения СЭБ;

$\Pi_{э б, i}$ - величина потерь предприятия от наступления угроз в случае реализации $i$-го сценария при внедрении СЭБ. 
Аналогичный вероятностный подход следует применять для определения значений всех показателей, входящих в качестве слагаемых в формулы (1) и (2). В частности, необходимо учитывать разные сценарии внедрения СЭБ, поскольку они будут различаться как по величине снижения потерь, так и по затратам на обеспечение функционирования СЭБ.

Для расчета ожидаемых значений потерь и экономического эффекта целесообразно использовать специально разработанные программные продукты, позволяющие моделировать будущие результаты при помощи метода Монте-Карло.

Мы введем дополнительное ограничение на показатель чистого экономического эффекта. Формально СЭБ может быть признана экономически эффективной при соблюдении условия $Э_{\text {ч }}>0$. Тем не менее, с точки зрения руководства предприятия, функционирование какой-либо системы оправданно только в том случае, если ее эффект не ниже определенной величины $Э_{\min }$. В случае СЭБ значение этого минимального экономического эффекта мы предлагаем рассчитывать по следующей формуле:

$$
\ni_{\min }=3_{э б}(1+r)
$$

где

$r$ - рентабельность предприятия.

В соответствии с этим условием, рентабельность СЭБ должна быть не ниже средней рентабельности предприятия. Это соответствует современной ориентации бизнеса на создание стоимости. Это указание не противоречит сформулированному нами выше утверждению о том, что оценка СЭБ при помощи показателя экономической эффективности (который по содержанию и методике расчета близок показателю рентабельности) неудобна для руководства предприятия. В формуле (3) мы отказываемся от прямого использования рентабельности-мы лишь применяем ее для расчета минимально допустимого экономического эффекта, т. е. переводим ее в удобный для руководства предприятия формат. Это полностью соответствует нашему подходу, согласно которому для оценки СЭБ следует использовать показатель экономического эффекта.

Рекомендовать к внедрению следует тот вариант СЭБ, для которого выполняется условие: 


$$
\left\{\begin{array}{l}
Э_{\mathrm{Y}} \rightarrow \max \\
Э_{\mathrm{u}} \geq Э_{\min }
\end{array}\right.
$$

Наряду с ожидаемым экономическим эффектом при оценке СЭБ необходимо принимать во внимание фактическое значение экономического эффекта $Э_{\phi}$, оцениваемое по результатам функционирования СЭБ:

$$
\ni_{\phi}=\Pi_{\Pi}+\Pi_{\mathrm{o}}-\Pi_{\mathrm{H}}-3_{э \tilde{\sigma}},
$$

где

$\Pi_{п}-$ возможные потери от угроз, которые удалось предотвратить благодаря внедрению СЭБ;

$\Pi_{\text {о }}$ - уменьшение потерь от реализовавшихся угроз, которого удалось добиться благодаря внедрению СЭБ;

$\Pi_{\text {н }}$ - потери от непредотвращенных угроз. Не удается предотвратить угрозы по следующим причинам: соответствующие угрозы не были предусмотрены при формировании СЭБ, угрозы были предусмотрены, но были выбраны неэффективные меры противодействия им, угрозы были предусмотрены и для противодействия им были разработаны адекватные мероприятия, но в силу какого-либо сбоя в СЭБ эти мероприятия не были реализованы.

Целесообразно ввести показатель результативности Р системы экономической безопасности, который будет рассчитываться по следующей формуле:

$$
\mathrm{P}=\frac{\ni_{\phi}}{\ni_{\min }} .
$$

При помощи показателя результативности СЭБ Р можно оценивать фактическую эффективность СЭБ (см. табл. 1).

Диагностическая таблица оценки фактической

Таблица 1.

экономической эффективности системы экономической безопасности предприятия нефтегазовой промышленности

\begin{tabular}{|c|c|c|}
\hline $\begin{array}{c}\text { Диапазон } \\
\text { значений } \\
\text { показателя Р }\end{array}$ & $\begin{array}{c}\text { Уровень } \\
\text { эффективности }\end{array}$ & \multicolumn{1}{|c|}{ Комментарии } \\
\hline $\mathrm{P} \geq 1$ & $\begin{array}{c}\text { Высокий уровень } \\
\text { эффективности }\end{array}$ & $\begin{array}{l}\text { При разработке СЭБ были учтены все возможные } \\
\text { угрозы, и СЭБ смогла всем им противодейство- } \\
\text { вать. Необходимости в доработке СЭБ нет }\end{array}$ \\
\hline
\end{tabular}


Окончание табл. 1.

\begin{tabular}{|c|c|l|}
\hline \multirow{2}{*}{$0 \leq \mathrm{P}<1$} & $\begin{array}{c}\text { Приемлемый уро- } \\
\text { вень эффектив- } \\
\text { ности }\end{array}$ & $\begin{array}{l}\text { СЭБ не смогла сократить ущерб от наступления } \\
\text { угроз до требуемого уровня, но при этом эффект } \\
\text { от ее функционирования положительный. СЭБ } \\
\text { нуждается в оптимизации с учетом реальной прак- } \\
\text { тики реализовавшихся угроз }\end{array}$ \\
\hline $\mathrm{P}<0$ & $\begin{array}{l}\text { Недопустимый } \\
\text { уровень эффектив- } \\
\text { ности }\end{array}$ & $\begin{array}{l}\text { Затраты на обеспечения СЭБ выше того уровня } \\
\text { потерь, которые она смогла предотратить. Мо- } \\
\text { дель функционирования СЭБ нуждается в ради- } \\
\text { кальном пересмотре с учетом фактического уров- } \\
\text { ня угроз }\end{array}$ \\
\hline
\end{tabular}

Важно отметить, что ситуации $\mathrm{P}<0$ могут соответствовать три принципиально разных состояния СЭБ:

1. Недостаточность СЭБ. В этом случае реальные угрозы, с которыми пришлось столкнуться СЭБ, значительно выше предусмотренных (низкая результативность СЭБ обуславливается высокими потерями от непредотвращенных угроз П

2. Избыточность СЭБ: реальный уровень угроз значительно ниже предусмотренного. Недостаточная эффективность СЭБ связана с тем, что размер предотвращенных потерь П и и П слишком мал;

3. Неэффективность СЭБ: высокий уровень потерь был связан в первую очередь с тем, что выбранные меры противодействия угрозам оказались неэффективными, а также с тем, что сама СЭБ функционирует неэффективно (ей присущи проблемы и сбои, которые препятствуют ей в противодействии угрозам).

Эти состояния идентифицируются на основании мониторинга СЭБ.

Следовательно, экономический эффект СЭБ во многом зависит от того, насколько качественно была проведена ее разработка, т. е. насколько точно были выявлена потенциальные угрозы экономической безопасности предприятия, насколько адекватными были выбранные меры, а также насколько качественно функционирует СЭБ.

Методика оценки экономической эффективности СЭБ представлена в табл. 2.

На этапе функционирования оценка экономической эффективности СЭБ не проводится: осуществляется лишь сбор информации об ее использовании. Разумеется, в случае явного несоответствия 
СЭБ уровню и составу угроз следует немедленно переходить от этапа функционирования к этапу анализа.

Таблийа 2.

Алгоритм оценки экономической эффективности СЭБ

\begin{tabular}{|c|c|c|}
\hline Этап & Состав & Комментарии \\
\hline \multirow{5}{*}{$\begin{array}{l}\text { Под- } \\
\text { готови- } \\
\text { тельный }\end{array}$} & $\begin{array}{l}\text { Прогнозирование по- } \\
\text { терь }\end{array}$ & Формирование сценариев реализации угроз \\
\hline & Разработка СЭБ & $\begin{array}{l}\text { Определение перспективных сценариев вне- } \\
\text { дрения СЭБ и оценка связанных с ними затрат }\end{array}$ \\
\hline & $\begin{array}{l}\text { Определение мини- } \\
\text { мального экономиче- } \\
\text { ского эффекта СЭБ } \\
\end{array}$ & $\begin{array}{l}\text { Расчет минимально допустимого значения } \\
\text { экономического эффекта СЭБ Этіn с учетом } \\
\text { требований к рентабельности предприятия }\end{array}$ \\
\hline & $\begin{array}{l}\text { Оценка экономиче- } \\
\text { ского эффекта СЭБ }\end{array}$ & $\begin{array}{l}\text { Расчет величины чистого экономического } \\
\text { эффекта Эч для всех сценариев реализации } \\
\text { угроз и для всех вариантов внедрения СЭБ }\end{array}$ \\
\hline & $\begin{array}{l}\text { Отбор варианта СЭБ } \\
\text { для внедрения }\end{array}$ & $\begin{array}{l}\text { Проводится отбор оптимального варианта } \\
\text { СЭБ по критерию максимума чистого эконо- } \\
\text { мического эффекта (формула (4)) }\end{array}$ \\
\hline \multirow{3}{*}{$\begin{array}{l}\text { Этап } \\
\text { функци- } \\
\text { ониро- } \\
\text { вания }\end{array}$} & Мониторинг СЭБ & $\begin{array}{l}\text { Оценка надежности СЭБ в ходе ее функцио- } \\
\text { нирования }\end{array}$ \\
\hline & $\begin{array}{l}\text { Идентификация неза- } \\
\text { планированных угроз }\end{array}$ & $\begin{array}{l}\text { Выявление угроз, которые не были определе- } \\
\text { ны на подготовительном этапе }\end{array}$ \\
\hline & $\begin{array}{l}\text { Оценка результатов } \\
\text { СЭБ }\end{array}$ & $\begin{array}{l}\text { Оценка фактической величины снижения по- } \\
\text { терь, достигнутой благодаря использованию } \\
\text { СЭБ }\end{array}$ \\
\hline \multirow[t]{4}{*}{$\begin{array}{l}\text { Этап } \\
\text { анализа }\end{array}$} & $\begin{array}{l}\text { Оценка результатив- } \\
\text { ности СЭБ }\end{array}$ & $\begin{array}{l}\text { Рассчитывается результативность СЭБ как } \\
\text { отношение фактического значения чистого } \\
\text { экономического эффекта к прогнозному }\end{array}$ \\
\hline & $\begin{array}{l}\text { Определение факти- } \\
\text { ческой эффективно- } \\
\text { сти СЭБ }\end{array}$ & $\begin{array}{l}\text { На основе значения результативности СЭБ } \\
\text { осуществляется шкалирование ее эффектив- } \\
\text { ности (см. табл. 1). Если СЭБ демонстрирует } \\
\text { высокий или приемлемый уровень эффек- } \\
\text { тивности, то оценка эффективности на этом } \\
\text { заканчивается. Если фактический уровень } \\
\text { эффективности неприемлемый, происходит } \\
\text { переход на следующий этап }\end{array}$ \\
\hline & Диагностика & $\begin{array}{l}\text { Выявление причин неприемлемого фактиче- } \\
\text { ского уровня эффективности }\end{array}$ \\
\hline & $\begin{array}{l}\text { Совершенствование } \\
\text { СЭБ }\end{array}$ & $\begin{array}{l}\text { Разработка рекомендаций по улучшению } \\
\text { функционирования СЭБ с учетом практики } \\
\text { ее использования }\end{array}$ \\
\hline
\end{tabular}


Отметим, что принимать решения о пересмотре структуры СЭБ в случае ее недостаточности или избыточности не следует по итогам одного периода ее функционирования - могло случиться так, что на этот период пришлись маловероятные события (слишком высокий или, наоборот, слишком низкий уровень угроз). Необходимо накопить определенную информационную базу для того, чтобы решение о пересмотре СЭБ было обоснованным. Напротив, если была выявлена неэффективность СЭБ, необходимо принимать срочные меры по устранению выявленных проблем.

\section{Обсуждение}

Таким образом, для оценки экономического эффекта СЭБ мы предлагаем использовать два показателя: чистый экономический эффект Э и иезультативность Р. У каждого из них есть своя сфера применения (см. рис. 1).

\begin{tabular}{|c|}
\hline $\begin{array}{c}\text { Чистый экономический } \\
\text { эффект Эч }\end{array}$ \\
\hline Применяется при \\
принятии решения о \\
внедрении СЭБ \\
\hline Критерий \\
оптимальности: \\
$\overbrace{\text { Э } \rightarrow \text { max }}$ \\
$Э_{ч} \geq Э_{\min }$ \\
\hline
\end{tabular}

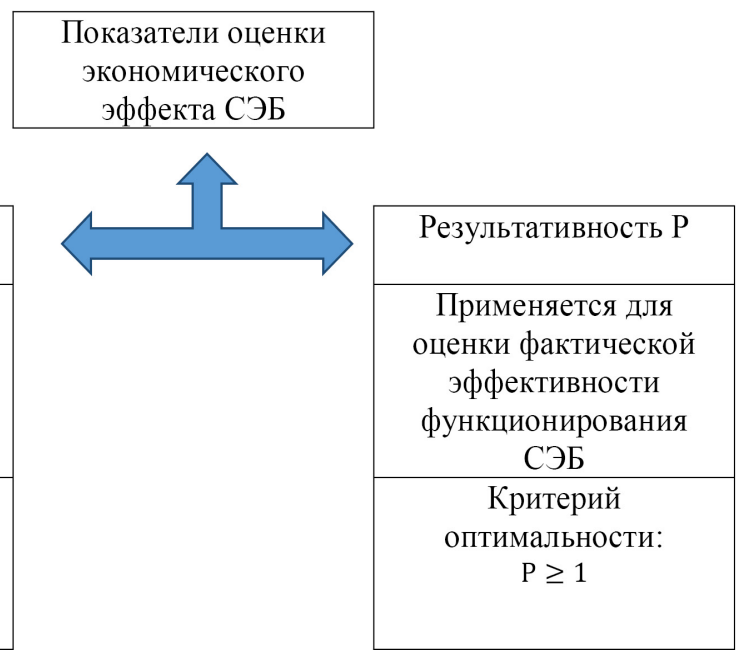

Рис. 1. Рекомендации по использованию показателей экономической эффективности системы экономической безопасности предприятия нефтегазовой промышленности.

Предложенная нами система показателей экономического эффекта СЭБ дает полное представление об экономических характе- 
ристиках СЭБ и позволяет принимать обоснованные решения о ее внедрении и пересмотре.

\section{Выводы}

Система экономической безопасности предприятия не позволяет получить прямой экономический эффект (в виде прибыли), она лишь позволяет снизить потери предприятия при наступлении угроз. По этой причине для оценки эффективности СЭБ можно рекомендовать показатель чистого экономического эффекта (а не экономической эффективности). Экономический смысл этого показателя заключается в том, что он представляет собой величину, на которую снизились потери предприятия благодаря использованию СЭБ (за вычетом затрат на функционирование СЭБ);

- для оценки фактической экономической эффективности СЭБ мы предлагаем использовать показатель результативности;

- показатель экономического эффекта следует использовать для принятия решения о выборе структуры СЭБ и о целесообразности ее внедрения, тогда как показатель результативности необходим для принятия решения о фактическом соответствии (или несоответствии) СЭБ тем угрозам экономической безопасности, с которыми сталкивается предприятие.

\section{Список литературы}

1. Богатырева С.В., Титов А.Б., Куприянова М.Ю. Экономическая эффективность как основа формирования управленческих решений // Экономика и менеджмент систем управления. 2016. Т. 20. № 2.1. C. $116-122$.

2. Бочуров А.А., Курбанов А.Х., Литвиненко А.Н. Сравнительный анализ отечественного и зарубежного опыта обеспечения экономической безопасности оборонно-промышленного комплекса // Известия Санкт-Петербургского государственного экономического университета. 2018. № 3. С. 99-106.

3. Вальдман Н.А., Маляренко Н.Л. Методические подходы к принятию решений по обеспечению безопасности шельфовых нефтегазовых 
объектов // Труды Крыловского государственного научного центра. 2020. № 1. С. 199-208.

4. Гайфуллина М.М., Костомарова Е.В. Методический подход к оценке экономической безопасности нефтяной компании // Интернет-журнал Науковедение. 2017. Т. 9. № 2. С. 11.

5. Герасимова М.В., Халикова М.А., Прокофьева П.Е. Вопросы формирования системы управления экономической безопасностью нефтяной компании // Управление экономическими системами: электронный научный журнал. 2018. № 11. С. 54.

6. Демкин И.В., Лесных В.В., Литвин Ю.В., Петрова М.С., Киркин М.А. Методический подход к комплексному анализу рисков нефтегазовых проектов // Проблемы экономики и управления нефтегазовым комплексом. 2014. № 4. С. 4-15.

7. Зайковский В.Э. Управление рисками газотранспортного предприятия (на примере ООО «Газпром Трансгаз Томск») // Проблемы экономики и управления нефтегазовым комплексом. 2014. № 4. С. 33-37.

8. Копотева А.В., Затонский А.В. Математическая модель выбора ресурсосберегающих мероприятий на промышленном предприятии в условиях риска // Управление финансовыми рисками. 2017. № 1. C. $60-70$.

9. Коротин В.Ю., Исламов Р.Т. Риск-ориентированное планирование структуры долга нефтяной компании // Проблемы экономики и управления нефтегазовым комплексом. 2014. № 12. С. 59-65.

10. Котляров И.Д. Аутсорсинговая модель организации российской нефтегазовой отрасли: проблемы и пути решения // Вопросы экономики. 2015. № 9. С. 45-64.

11. Пермякова Т.В., Файзуллин Р.В. Анализ влияния санкций США и ЕС на разработку новых нефтяных месторождений в России и пути решения проблемы // Вестник ИжГТУ им. М. Т. Калашникова. 2015. T. 18. № 1. C. 65-66.

12. Плотников В.А., Кутепова М.В. Управление экономической безопасностью нефтяных компаний (на примере оценки и снижения рисков реализации проектов освоения нефтяных месторождений Арктического региона России) // Известия Юго-Западного государственного 
университета. Серия: Экономика. Социология. Менеджмент. 2017. T. 7. № 1. С. 39-49.

13. Плотников В.А., Рукинов М.В. Новый облик мировой энергетики и экономическая безопасность России // Известия высших учебных заведений. Серия: Экономика, финансы и управление производством. 2020. № 2. C. 39-43.

14. Редина М.М. Прогноз влияния внешних факторов на характер эколого-экономической устойчивости нефтегазовых компаний // Проблемы экономики и управления нефтегазовым комплексом. 2011. № 5. С. 22-25.

15. Симонов С.Г., Ямова О.В. Критерии и показатели оценки уровня экономической безопасности крупных компаний нефтегазового профиля // Вестник Омского университета. Серия: Экономика. 2018. № 4. С. 57-67.

16. Шевелева А.В., Галкин С.А. Опыт управления рисками инвестиционных проектов в практике российских нефтегазовых компаний // Управление риском. 2019. № 2. С. 43-52.

\section{References}

1. Bogatyreva S.V., Titov A.B., Kupriyanova M.Yu. Ekonomicheskaya effektivnost kak osnova formirovaniya upravlencheskikh resheniy [Economic effectiveness as a basis for managerial decisions]. Ekonomika $i$ menedzhment system upravleniya, 2016, V. 20, no 2.1, pp. 116-122.

2. Bochurov A.A., Kurbanov A.Kh., Litvinenko A.N. Sravnitelnyy analiz otechestvennogo i zarubezhnogo opyta obespecheniya ekonomicheskoy bezopasnosti oboronno-promyshlennogo kompleksa [A comparative analysis of the Russian and international experience of the ensuring of the economic security of the defence industrial complex]. Izvestiya Sankt-Peterburgskogo gosudarstvennogo ekonomicheskogo universiteta, 2018, no 3, pp. 99-106.

3. Valdman N.A., Malyarenko N.L. Metodicheskie podkhody k prinyatiyu resheniy po obespecheniyu bezopasnosti shelfovykh neftegazovykh ob'yektov [Methodological approaches towards decision making in the field of security of shelf oil and gas object]. Trudy Krylovskogo gosudarstvennogo nauchnogo tsentra, 2020, no 1, pp. 199-208. 
4. Gayfullina M.M., Kostomarova E.V. Metodicheskiy podkhod k otsenke ekonomicheskoy bezopasnosti neftyanoy kompanii [A methodological approach towards evaluation of economic security of an oil company]. Internet-zhurnal Naukovedenie, 2017, V. 9, no 2, pp. 11.

5. Gerasimova M.V., Khalikova M.A., Prokof'yeva P.E. Voprosy formirovaniya sistemy upravleniya ekonomiccheskoy bezopasnost'yu neftyanoy kompanii [Problems of formation of the system of economic security management of an oil company]. Upravlenie ekonomicheskimi sistemami: elektronnyy nauchnyy zhurnal, 2018, no 1, pp. 54.

6. Demkin I.V., Lesnykh V.V., Litvin Yu.V., Petrova M.S., Kirkin M.A. Metodicheskiy podkhod k kompleksnomu analizu riskov neftegazovykh proektov [A methodological approach towards complex analysis of risks of oil and gas projects]. Problemy ekonomiki i upravleniya neftegazovym kompleksom, 2014, no 4, pp. 4-15.

7. Zaykovskiy V.E. Upravlenie riskami gazotransportnogo predpriyatiya (na primere OOO "Gazprom Transgaz Tomsk") [Risk management of a gas transporting company (OOO "Gazprom Transgaz Tomsk" case)]. Problemy ekonomiki i upravleniya neftegazovym kompleksom, 2014, no 4, pp. 33-37.

8. Kopoteva A.V., Zatonskiy A.V. Matematicheskaya model vybora resursosberegayushchikh meropriyatiy na promyshlennom predpriyatii $\mathrm{v}$ usloviyakh riska [A mathematical model of selection of resource saving measures for an industrial company under risk]. Upravlenie finansovymi riskami, 2017, no 1, pp. 60-70.

9. Korotin V.Yu., Islamov R.T. Risk-orientirovannoe planirovanie struktury dolga neftyanoy kompanii [Risk-oriented planning of the debt structure of an oil company]. Problemy ekonomiki i upravleniya neftegazovym kompleksom, 2014, no 12, p. 59-65.

10. Kotliarov I.D. Autsorsingovaya model organizatsii rossiyskoy neftegazovoy otrasli: problemy i puti razvitiya [Outsourcing model of organization of the Russian oil and gas industry: problems and ways of solution]. Voprosy ekonomiki, 2015, no 9, pp. 45-64.

11. Permyakova T.V., Fayzullin R.V. Analiz vliyaniya sanktsiy SSHA i ES na razrabotku novykh neftyanykh mestorozhdeniy $\mathrm{v}$ Rossii i puti resh- 
eniya problemy [An analysis of the impact of the US and EU sanctions on the exploitation of new oil reserves in Russia and ways of solution of the problem]. Vestnik IZHGTU im. M. T. Kalashnikova, 2015, V. 18, no 1, pp. 65-66.

12.Plotnikov V.A., Kutepova M.V. Upravlenie ekonomicheskoy bezopasnost'yu neftyanykh kompaniy (na primere otsenki i snizheniya riskov realizatsii proektov osvoeniya neftyanykh metorozhdeniya Arkticheskogo regiona Rossii) [Economic security management of oil companies (on the example of risk evaluation and decrease of the risk of implementation of projects of exploitation of oil reserves of the Arctic region of Russia)]. Izvestiya Yugo-Zapadnogo gosudarstvennogo universiteta. Seriya: Ekonomika. Sotsiologiya. Menedzhment, 2017, V. 7, no 1, pp. 39-49.

13. Plotnikov V. A., Rukinov M.V. Novyy oblik mirovoy energetiki i ekonomicheskaya bezopasnost Rossii [The new structure of the global energy sector and economic security of Russia]. Izvestiya vysshikh uchebnykh zavedeniy. Seriya: Ekonomika, finansy i upravlenie proizvodstvom, 2020, no 2, pp. 39-43.

14. Redina M.M. Prognoz vliyaniya vneshnikh faktorov na kharakter ekologo-ekonomicheskoy ustoychivosti neftegazovykh kompaniy [Forecasting of the impact of external factors on the character of economic and ecological stability of oil and gas companies]. Problemy ekonomiki i upravleniya neftegazovym kompleksom, 2011, no 5, pp. 22-25.

15. Simonov S.G., Yamova O.V. Kriterii i pokazateli otsenki urovnya ekonomicheskoy bezopasnosti krupnykh kompaniy neftegazovogo profilya [Criteria and indices of evaluation of the level of economic security of big companies of oil and gas industry]. Vestnik Omskogo universiteta. Seriya: Ekonomika, 2018, no 4, pp. 57-67.

16. Sheveleva A.V., Galkin S.A. Opyt upravleniya riskami investitsionnykh proektov v praktike rossiyskikh neftegazovykh kompaniy [Experience of investment project risk management in the practice of Russian oil and gas companies]. Upravlenie riskom, 2019, no 2, pp. 43-52. 


\section{ДАННЫЕ ОБ АВТОРЕ}

Жуков Иван Федорович, аспирант

Санкт-Петербургский университет Государственной противопожарной службы Министерства Российской Федерации по делам гражданской обороны, чрезвычайным ситуациям и ликвидации последствий стихийных бедствий ivan-zhukov-1995@mail.ru

\section{DATA ABOUT THE AUTHOR}

\section{Zhukov Ivan Fedorovich, Cand. Sc. Student}

St. Petersburg University of the State Fire Service of the Ministry of the Russian Federation for Civil Defence, Emergencies and Elimination of Consequences of Natural Disasters ivan-zhukov-1995@mail.ru 